\title{
Comparison of complete and near-complete endovascular embolization of hypervascular spine tumors with partial embolization
}

\author{
Erick M. Westbroek, MD, Zach Pennington, BS, ${ }^{1}$ A. Karim Ahmed, BS, ${ }^{1}$ Yuanxuan Xia, MD, ${ }^{1}$ \\ Christine Boone, MD, PhD, ${ }^{2}$ Philippe Gailloud, MD, ${ }^{3}$ and Daniel M. Sciubba, MD' \\ Departments of ${ }^{1}$ Neurosurgery and ${ }^{3}$ Neuroradiology, Johns Hopkins University School of Medicine, Baltimore, Maryland; and \\ ${ }^{2}$ Department of Interventional Radiology, University of California, San Diego School of Medicine, San Diego, California
}

\begin{abstract}
OBJECTIVE Preoperative endovascular embolization of hypervascular spine tumors can reduce intraoperative blood loss. The extent to which subtotal embolization reduces blood loss has not been clearly established. This study aimed to elucidate a relationship between the extent of preoperative embolization and intraoperative blood loss.
\end{abstract}

METHODS Sixty-six patients undergoing preoperative endovascular embolization and subsequent resection of hypervascular spine tumors were retrospectively reviewed. Patients were divided into 3 groups: complete embolization $(n=$ 22), near-complete embolization ( $\geq 90 \%$ but $<100 \% ; n=22$ ), and partial embolization $(<90 \% ; n=22)$. Intraoperative blood loss was compared between groups using one-way ANOVA with post hoc comparisons between groups.

RESULTS The average blood loss in the complete embolization group was $1625 \mathrm{~mL}$. The near-complete embolization group had an average blood loss of $2021 \mathrm{~mL}$ in surgery. Partial embolization was associated with a mean blood loss of $4009 \mathrm{~mL}$. On one-way ANOVA, significant differences were seen across groups (F-ratio $=6.81, p=0.002$ ). Significant differences in intraoperative blood loss were also seen between patients undergoing complete and partial embolization $(p=0.001)$ and those undergoing near-complete and partial embolization $(p=0.006)$. Pairwise testing showed no significant difference between complete and near-complete embolization $(p=0.57)$. Analysis of a combined group of complete and near-complete embolization also showed a significantly decreased blood loss compared with partial embolization ( $p$ $<0.001$ ). Patient age, tumor size, preoperative coagulation parameters, and preoperative platelet count were not significantly associated with blood loss.

CONCLUSIONS Preoperative endovascular embolization is associated with decreased intraoperative blood loss. In this series, blood loss was significantly less in surgeries for tumors in which preoperative complete or near-complete embolization was achieved than in tumors in which preoperative embolization resulted in less than $90 \%$ reduction of tumor vascular blush. These findings suggest that there may be a critical threshold of efficacy that should be the goal of preoperative embolization.

https://thejns.org/doi/abs/10.3171/2020.1.SPINE191337

KEYWORDS spine oncology; hypervascular metastases; preoperative embolization; vascular anatomy

$\mathrm{B}$ ECAUSE of improvements in systemic oncological disease management, there is an increasing population of patients with indications for surgical management of vertebral metastases. ${ }^{1,2}$ One concern during resection of spinal tumors is intraoperative blood loss, which can be in excess of $3 \mathrm{~L} .{ }^{3}$ Blood loss is of particular concern in a certain subset of tumors that are considered to be hypervascular, ${ }^{4}$ of which the most common type is renal cell carcinoma. In addition to the immediate intra- operative risks posed by intraoperative hemorrhage, major blood loss is also associated with poor wound healing and postoperative infection. ${ }^{5,6}$

Preoperative tumor embolization is one option for decreasing blood loss in surgery? Previous studies have shown preoperative embolization to decrease intraoperative blood loss, transfusion requirements, and the occurrence of major intraoperative hemorrhage. ${ }^{8,9}$ These benefits are most pronounced if surgery is performed within

ABBREVIATIONS NBCA $=$ N-butyl cyanoacrylate.

SUBMITTED November 7, 2019. ACCEPTED January 27, 2020.

INCLUDE WHEN CITING Published online April 3, 2020; DOI: 10.3171/2020.1.SPINE191337. 
48 hours of embolization. ${ }^{9}$ Additionally, despite concerns regarding the risk of spinal cord ischemia secondary to nontarget embolization, multiple studies have demonstrated intraoperative embolization to be safe when performed at high-volume centers. ${ }^{8,10}$

Even at high-volume centers, complete embolization is often impossible, such as in cases in which a tumorfeeding vessel shares a common origin with a radiculomedullary artery. One outstanding question in the literature is how the degree of tumor embolization impacts intraoperative blood loss. The purpose of this study was to evaluate this endpoint, specifically, to determine whether intraoperative blood loss was correlated with the extent of preoperative tumor embolization. As a portion of this, we specifically sought to investigate if near-complete embolization (defined as $90 \%-100 \%$ reduction in vascular blush) provided similar outcomes to those of complete embolization. A better understanding between extent of embolization and intraoperative blood loss would allow for better risk-benefit analysis, maximizing the utility of this important technique.

\section{Methods}

\section{Patient Inclusion and Study Design}

This retrospective study was performed after we received Johns Hopkins Medicine IRB approval. All patients who underwent preoperative endovascular embolization and subsequent resection for hypervascular tumors of the spine at a single academic institution were identified during a 12-year period, from 2005 to 2017. At our institution, patients with pathologically diagnosed hypervascular spine tumors are evaluated with CT angiography prior to surgery. Diagnoses most frequently evaluated for hypervascularity include renal cell carcinoma, atypical hemangioma, thyroid carcinoma, pheochromocytoma, hematogenous malignancies (i.e., multiple myeloma, plasmacytoma, hemangioma, angiosarcoma), sarcomas, hepatocellular carcinoma, and melanoma. The extent of resection (i.e., laminectomy, vertebrectomy, spondylectomy) is determined by the primary surgeon on a case-by-case basis depending on the primary tumor etiology, symptomatology, surgical feasibility, systemic burden, and life expectancy.

Patients with sufficient electronic medical records, pathologic diagnosis of tumor, preoperative imaging studies, CT angiograms, fluoroscopic angiograms from preand postembolization time points, embolization records, and operative details were included. Patients undergoing coil and/or glue embolization were determined to be appropriate for inclusion. Exclusion criteria were insufficient medical records, imaging studies, embolization reports, operative reports, or clinical follow-up.

\section{Data Collection}

Demographic, clinical, and embolization details were collected for each patient. Demographic information consisted of age, sex, and known history of vascular disease. Tumor etiology, spinal location, and spinal compartment (intramedullary, intradural-extramedullary, or extradural) were collected. Details of preoperative embolization pro- cedures were recorded, including material used for embolization ( $N$-butyl cyanoacrylate [NBCA] glue or coil), and extent of embolization. Extent of embolization was evaluated based on the report of the performing interventionalist (P.G.). The report was then confirmed jointly by the first author (E.M.W.) and performing interventionalist (P.G.) by review of the fluoroscopy images available in our institutional PACS system. Patients were divided into 3 groups based on the decrease in peritumoral vascular blush as seen on fluoroscopic angiography: complete embolization (100\%), near-complete embolization $(\geq 90 \%$ but $<100 \%)$, and partial embolization $(<90 \%)$. Intraoperative blood loss was collected for all patients. Length of follow-up, survival, and preprocedural and postprocedural neurological status were collected.

\section{Statistical Analysis}

Means between groups were first evaluated with oneway ANOVA. Subsequent pairwise comparisons were made using the Student t-test; $p<0.05$ was considered statistically significant. Analysis was performed using Stata SE 12 (StataCorp LLC).

\section{Results}

We identified 174 patients with hypervascular lesions who underwent resection in the period reviewed, of whom 91 were evaluated for preoperative embolization of their lesion (Fig. 1). Sixty-six patients met inclusion criteria. Clinical demographic information is summarized in Table 1. The mean age at the time of surgery was $53.6 \pm 13.3$ years (range 26-76 years). Forty-three patients were male (65.2\%); 23 patients were female (34.8\%). Seven patients $(10.6 \%)$ had a history of vascular disease. The thoracic spine was the most common location of disease (38 patients, 57.6\%), followed by the lumbar spine (18 patients, $27.3 \%$ ), and cervical spine (8 patients, $12.1 \%)$. Sacral disease was uncommon within the cohort (2 patients, 3.0\%). Pathologies in the series included renal cell carcinoma (26 patients, 39.4\%); hemangioma (9 patients, 13.6\%); thyroid carcinoma (6 patients, 9.1\%); paraganglioma (4 patients, $6.1 \%$ ); pheochromocytoma (3 patients, $4.5 \%$ ); multiple myeloma (3 patients, $4.5 \%$ ); neuroendocrine carcinoma (2 patients, $3.0 \%$ ); hepatocellular carcinoma (2 patients, $3.0 \%$ ); and epithelioid hemangioma, synovial sarcoma, breast carcinoma, urothelial carcinoma, hemangiopericytoma, gastroesophageal junction carcinoma, leiomyosarcoma, melanoma, schwannoma, angiosarcoma, myxopapillary ependymoma, and giant cell tumor (1 patient each, $1.5 \%$ [Table 2]).

Twenty-two patients (33.3\%) had complete embolizations, with no residual tumor blush. Another 22 patients (33.3\%) had near-complete embolizations, defined as greater than or equal to $90 \%$ but less than $100 \%$ embolization. Finally, 22 patients (33.3\%) underwent partial embolization, meaning that less than $90 \%$ of the tumor was embolized (Fig. 2). Fifteen patients (22.7\%) underwent coil embolization alone, 10 patients (15.2\%) underwent glue embolization alone, and 31 patients (47.0\%) had both coils and glue placed during embolization. Embospheres were used in 6 patients $(9.1 \%)$. Polyvinyl alcohol particles were 


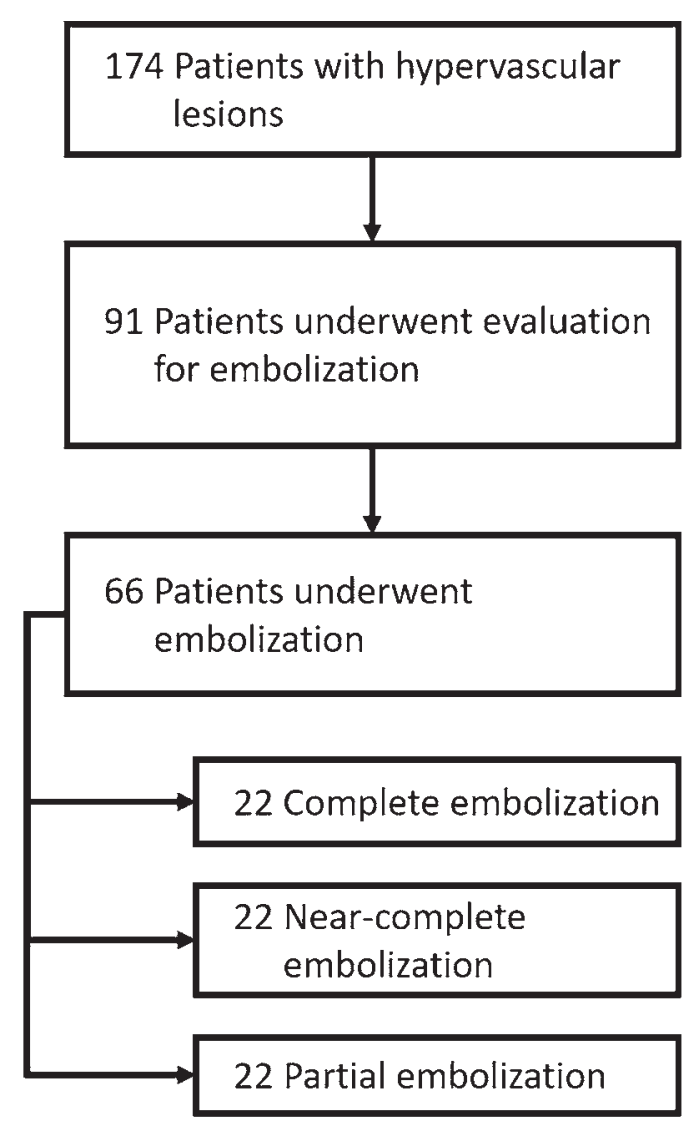

FIG. 1. Flowchart illustrating selection of patients for final analysis.

utilized in 4 cases (6.1\%) (Table 3). All embolizations were performed by a single neurointerventionalist. One complication occurred due to embolization. A coil placed in an L1 intersegmental artery dislodged and wedged subocclusively in the patient's left popliteal artery. No patient demonstrated clinical or radiographic signs of spinal cord ischemia postoperatively.

Patients with complete embolization had a mean blood loss of $1625 \pm 1696 \mathrm{~mL}$ at surgery (median $1300 \mathrm{~mL}$,

TABLE 1. Demographics in 66 patients who underwent preoperative endovascular embolization of their spine tumors

\begin{tabular}{cc}
\hline & Value \\
\hline Mean age, yrs (range) & $53.6 \pm 13.3(26-76)$ \\
\hline Male sex & $43(65.2)$ \\
\hline Hx vascular disease & $7(10.6)$ \\
\hline Location & \\
\hline Cervical & $8(12.1)$ \\
\hline Thoracic & $38(57.6)$ \\
\hline Lumbar & $18(27.3)$ \\
\hline Sacral & $2(3.0)$ \\
\hline Intraop vessel injury & $3(4.5)$ \\
\hline
\end{tabular}

$\mathrm{Hx}=$ history of.

Values represent the number of patients (\%) unless indicated otherwise.
TABLE 2. Tumor etiology

\begin{tabular}{lc}
\hline \multicolumn{1}{c}{ Pathology } & No. of Patients (\%) \\
\hline Renal cell carcinoma & $26(39.4)$ \\
\hline Hemangioma & $9(13.6)$ \\
\hline Thyroid carcinoma & $6(9.1)$ \\
\hline Paraganglioma & $4(6.1)$ \\
\hline Pheochromocytoma & $3(4.5)$ \\
\hline Multiple myeloma & $3(4.5)$ \\
\hline Neuroendocrine & $2(3.0)$ \\
\hline Hepatocellular carcinoma & $2(3.0)$ \\
\hline Epithelioid hemangioma & $1(1.5)$ \\
\hline Synovial sarcoma & $1(1.5)$ \\
\hline Breast adenocarcinoma & $1(1.5)$ \\
\hline Urothelial carcinoma & $1(1.5)$ \\
\hline Hemangiopericytoma & $1(1.5)$ \\
\hline Gastroesophageal adenocarcinoma & $1(1.5)$ \\
\hline Leiomyosarcoma & $1(1.5)$ \\
\hline Melanoma & $1(1.5)$ \\
\hline Angiosarcoma & $1(1.5)$ \\
\hline Myxopapillary ependymoma & $1(1.5)$ \\
\hline Giant cell tumor & $1(1.5)$ \\
\hline
\end{tabular}

range 450-8000 $\mathrm{mL}$; Table 4). The near-complete embolization group had a mean intraoperative blood loss of $2021 \pm 1531 \mathrm{~mL}$ (median $1600 \mathrm{~mL}$, range 200-6000 $\mathrm{mL}$ ). Patients with only partial embolization had a mean blood loss of $4009 \pm 3222 \mathrm{~mL}$ at surgery (median 3750 $\mathrm{mL}$, range 200-10,000 mL). Comparisons across groups in one-way ANOVA testing showed a significant association between extent of embolization and intraoperative blood loss (F-ratio 6.81; $\mathrm{p}=0.002$ ). Pairwise post hoc testing showed that both complete embolization $(\mathrm{p}=0.001)$ and near-complete embolization $(\mathrm{p}=0.006)$ significantly reduced intraoperative blood loss relative to partial embolization. However, there was no significant difference between complete and near-complete embolization ( $\mathrm{p}=$ 0.57). Analysis of the complete and near-complete groups combined also showed a statistically significant reduction in blood loss compared with partial embolization ( $\mathrm{p}$ $<0.001$ ). Additionally, we found that intraoperative vessel injury was associated with a significant increase in intraoperative blood loss (mean $5500 \pm 2500$ vs $2418 \pm$ $2420 \mathrm{~mL}, \mathrm{p}=0.04$ ). Univariable linear regression showed a significant correlation between tumor volume and intraoperative blood loss $(r=0.34 ; p=0.006)$. We saw no association of primary tumor pathology $(p=0.16)$, history of vascular disease $(\mathrm{p}=0.56)$, sex $(\mathrm{p}=0.86)$, or preoperative laboratory data $(\mathrm{p}=0.12-0.26)$ with intraoperative blood loss. However, lower platelet count did trend toward being associated with increased intraoperative blood loss ( $\mathrm{r}$ $=-0.20 ; \mathrm{p}=0.12$ ).

The average length of follow-up was 50 months (range 1-165 months). Twenty-nine patients (42.6\%) died during the follow-up period. On initial postoperative examination, 20 patients (30.3\%) had an improvement of at least 

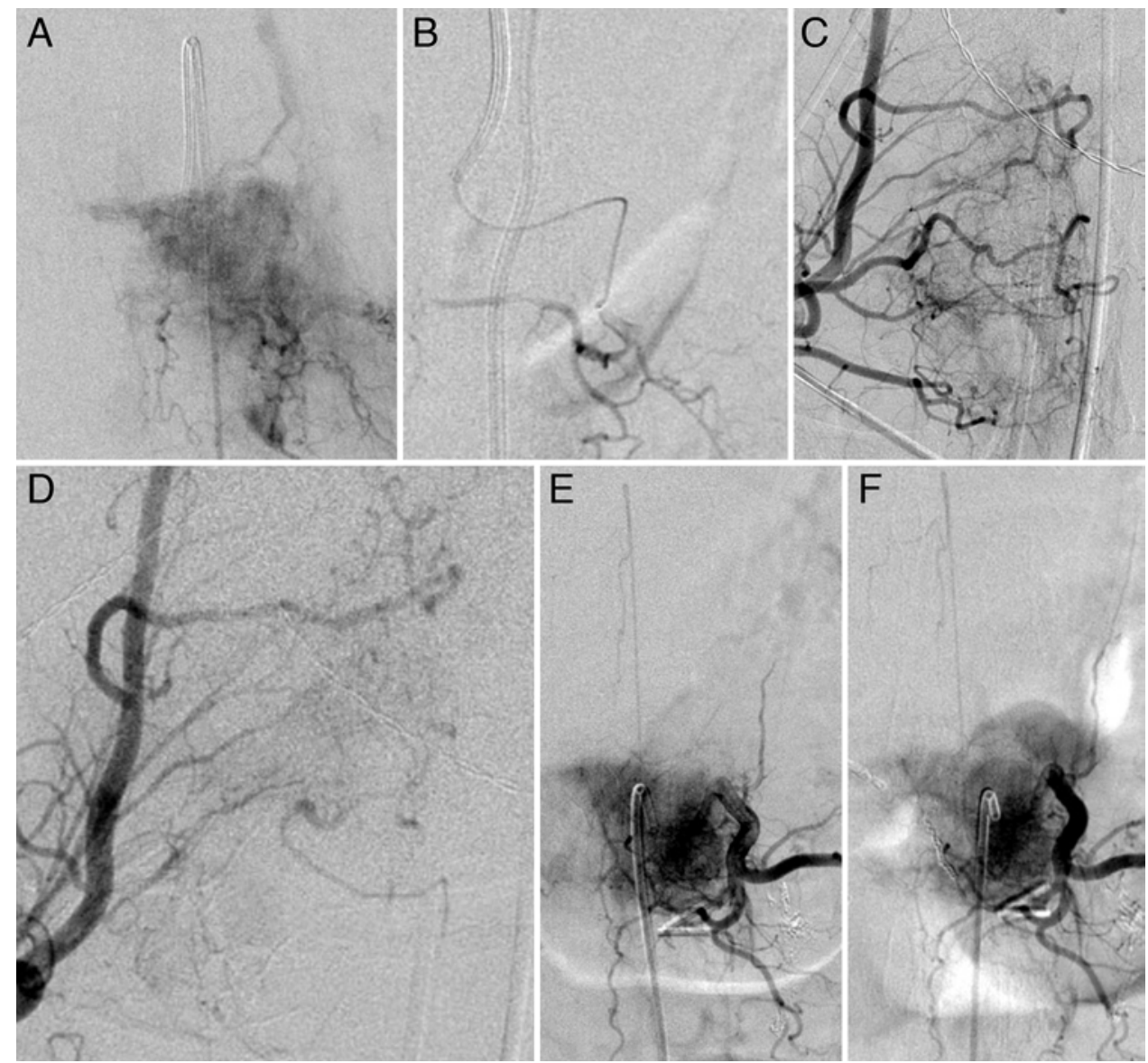

FIG. 2. Representative cases from each embolization outcome group. A: Angiogram obtained in a 49-year-old woman with breast adenocarcinoma metastasis to L1 that was found to be unusually hypervascular on MRI. Tumor blush is visible at L1 during angiography. B: After embolization with NBCA and coils, no residual tumor blush is visible. C: Angiogram obtained in a 33-yearold female with leiomyosarcoma metastatic to T1. Injection of the right costocervical trunk confirmed tumor blush at T1. D: After embolization of the accessible tumor-feeding branches with NBCA, greater than $90 \%$ of the tumor blush is no longer visible.

E: Angiogram obtained in a 50-year-old male with renal cell carcinoma metastatic to L1. The angiogram shows tumor blush as well as the radiculomedullary artery. F: After coiling of tumor-feeding branches distal to the origin of the radiculomedullary artery, tumor blush was decreased by approximately $40 \%$.

one ASIA (American Spinal Injury Association) grade. Forty-six patients $(69.7 \%)$ had unchanged ASIA grades. No patient $(0 \%)$ worsened in the immediate postoperative period.

\section{Discussion}

Surgical management of neoplastic disease of the spine is becoming an increasingly important aspect of cancer care. This is particularly relevant with metastatic disease as the population ages with concomitant improvement in systemic cancer therapies. ${ }^{11,12}$ The main goals of spine tumor surgery include reduction of local tumor burden, relief of pain, decompression of neural elements, restoration and preservation of neurological function, and stabilization of the spine..$^{11,13-16}$

Hypervascular spine tumors are particularly difficult to treat, given their associated risk of high intraoperative blood loss. ${ }^{4}$ Preoperative endovascular embolization of such tumors has been demonstrated in multiple studies to be both safe and effective in reducing intraoperative blood loss. ${ }^{17-19}$ There are, however, conflicting reports regarding the degree to which extent of embolization affects blood loss at surgery.

A study by Kato et al. reviewed a series of 46 patients. ${ }^{20}$ Complete embolization in that study was defined as $>90 \%$. Partial embolization was defined as $90 \%$ or less. The authors reported no significant difference in surgical blood loss between partial and complete groups, although both groups had significantly less blood loss than the group that underwent surgery without preoperative embolization.

Another series of 62 patients reported on by Kobayashi et al. also found no significant difference in surgical blood loss related to the extent of embolization. ${ }^{21}$ Complete embolization was defined as greater than or equal to $90 \%$. Partial embolization was defined as less than $90 \%$.

Griessenauer et al. published a meta-analysis of factors associated with intraoperative blood loss in hypervascular spine tumors. ${ }^{22}$ They found that complete embolization, defined as $>80 \%$, was not associated with decreased blood 
TABLE 3. Embolization results

\begin{tabular}{cc}
\hline & No. of Patients (\%) \\
\hline Embolization & $22(33.3)$ \\
\hline Complete & $22(33.3)$ \\
\hline Near-complete & $22(33.3)$ \\
\hline Partial & \\
\hline Embolic material & $15(22.7)$ \\
\hline Coils & $10(15.2)$ \\
\hline Glue & $31(47.0)$ \\
\hline Coils \& glue & $6(9.1)$ \\
\hline Embospheres & $4(6.1)$ \\
\hline Polyvinyl alcohol
\end{tabular}

loss in comparison with partial embolization. Interestingly, they found, over the time period studied, that intraoperative blood loss was decreasing in more contemporary studies, but the extent of embolization was not increasing. The authors concluded that improved surgical techniques combined with tempered surgical goals (e.g., subtotal resection followed by radiation therapy) were the main drivers of decreased blood loss up to that point in time.

Contrary to these earlier papers, a more contemporary study by Tan et al. reported that the extent of embolization was associated with surgical blood loss. ${ }^{23}$ They reported a series of 221 patients, comparing 3 groups: complete (defined as $>80 \%$ ), subtotal (defined as $50 \%-80 \%$ ), and partial $(<50 \%)$. The authors found that $>80 \%$ embolization was associated with significantly decreased blood loss compared with $<80 \%$. The subtotal and partial embolization groups were not statistically different from one another. The contradictory findings of these authors relative to those of other groups may stem from varying definitions of complete embolization, or related to new techniques developed in recent years.

One key unaddressed question thus far is whether truly complete embolization, defined as $100 \%$ absence of tumor blush after embolization, confers any additional benefit compared with near-complete embolization. Both metastatic tumor- and primary tumor-feeding vessels can frequently be associated with radiculomedullary arteries, making spinal cord stroke a significant risk of embolization procedures. ${ }^{24,25}$ Embolization of such tumor-feeding vessels is possible if superselective catheterization can be obtained distal to the radiculomedullary origin. Understanding the benefit, or lack thereof, of complete embolization will help interventionalists better assess the riskbenefit ratio during embolization procedures.

In this report, we retrospectively reviewed 66 patients who underwent embolization of hypervascular spine tumors prior to surgery. We divided patients into 3 groups. Roughly one-third of our cohort had complete occlusion of tumor blush after embolization. A cutoff of $90 \%$ embolization was used for the near-complete group for 2 reasons. First, as noted in the studies published by Kato et al. ${ }^{9}$ and Kobayashi et al., ${ }^{21} 90 \%$ embolization has frequently been used as a cutoff defining the upper limit of partial
TABLE 4. Surgical results and statistical analysis

\begin{tabular}{|c|c|c|}
\hline & Mean Blood Loss & p Value \\
\hline Extent of embolization* & & 0.002 \\
\hline Complete & $1625 \pm 1696$ & \\
\hline Near-complete & $2021 \pm 1531$ & \\
\hline Partial & $4009 \pm 3222$ & \\
\hline \multicolumn{3}{|l|}{ Comparison btwn groups } \\
\hline Complete vs near-complete & & 0.57 \\
\hline Complete vs partial & & 0.001 \\
\hline Near-complete vs partial & & 0.006 \\
\hline Complete or near-complete vs partial & & $<0.001$ \\
\hline \multicolumn{3}{|l|}{ Other variables } \\
\hline Sex & & 0.86 \\
\hline Male & $2519 \pm 2351$ & \\
\hline Female & $2638 \pm 2798$ & \\
\hline $\mathrm{Hx}$ vascular disease & & 0.56 \\
\hline Yes & $2036 \pm 1746$ & \\
\hline No & $2623 \pm 2570$ & \\
\hline Intraop vessel injury & & 0.04 \\
\hline Yes & $5500 \pm 2500$ & \\
\hline No & $2418 \pm 2420$ & \\
\hline Spine level & & 0.23 \\
\hline Cervical & $3475 \pm 3208$ & \\
\hline Thoracic & $2109 \pm 1859$ & \\
\hline Lumbosacral & $3028 \pm 3093$ & \\
\hline Primary pathology & & 0.16 \\
\hline Renal cell carcinoma & $2222 \pm 2217$ & \\
\hline Thyroid carcinoma & $3791 \pm 3498$ & \\
\hline Vascular lesion & $1491 \pm 1318$ & \\
\hline Other & $3118 \pm 2769$ & \\
\hline Univariable Correlations & r & p Value \\
\hline Age & 0.20 & 0.12 \\
\hline Tumor vol & 0.34 & 0.006 \\
\hline Day btwn embolization \& surgery & 0.04 & 0.77 \\
\hline \multicolumn{3}{|l|}{ Preop labs } \\
\hline PT & 0.14 & 0.26 \\
\hline INR & 0.10 & 0.41 \\
\hline aPTT & 0.12 & 0.35 \\
\hline Platelet count & -0.20 & 0.12 \\
\hline
\end{tabular}

aPTT = adjusted partial thromboplastin time; INR = international normalized ratio; $\mathrm{PT}=$ prothrombin time.

*One-way ANOVA: F-ratio 6.81; $p=0.002$ for comparisons across groups of extent of embolization and intraoperative blood loss.

embolization, and thus this choice of cutoff would help our results fit into the existing literature. Second, choosing this cutoff in our cohort leads to 3 groups of equal sizes, improving statistical comparisons.

Similar to Tan et al. ${ }^{23}$ and Kumar et al., ${ }^{26}$ we found that near-complete and complete embolization were associated with significantly reduced blood loss at surgery, both in individual comparisons and as a combined group. Impor- 
tantly, we found no significant difference between complete and near-complete embolization. This suggests that there may be some minimum effective degree of embolization above which little additional benefit is conferred. Such a threshold may be below $90 \%$, considering that Kumar et al. found a significant reduction in blood loss at $80 \%$ embolization. In practice, our findings promote a cautious approach during embolization. There may exist some point above which the risk of further embolization, particularly in feeders that also give rise to a radiculomedullary artery, may convey no additional benefit.

In our experience, obtaining complete or near-complete obliteration of the vessels feeding the target lesion requires the use of liquid embolic agents in addition to mechanical agents, such as coils. Popular agents currently in use include NBCA-Ethiodol copolymers, and ethylene-vinyl alcohol-dimethylsulfoxide copolymers. ${ }^{27}$ The chief benefit of these agents is that they allow for superior tumor bed penetration and consequently may increase the likelihood of complete devascularization..$^{22}$ Liquid agents also have the advantage of not relying on the patient's intrinsic coagulation system, ${ }^{27}$ meaning that they can still be employed in patients with acquired bleeding diatheses, which are seen in up to $10 \%$ of patients with solid tumors. ${ }^{28}$ The largest drawback to these agents is that they have been noted to have more difficult handling properties relative to nonabsorbable microparticles and mechanical embolic agents, such as coils. ${ }^{27}$ In the case of the NBCA-Ethiodol mixture used here, these properties can be significantly altered by modifying the NBCA-Ethiodol mixture. ${ }^{29}$ To this end, the present results suggest that with the correct mixture, liquid agents such as NBCA-Ethiodol can produce good results.

There was one complication (1.5\%) from the embolization procedures in this series. In this case, the patient was noted to have an approximately $6-\mathrm{g} / \mathrm{dL}$ decrease in his hemoglobin from baseline (from 14.7 to $8.9 \mathrm{~g} / \mathrm{dL}$ ). Follow-up imaging failed to demonstrate a hematoma in the region of the thrombosed vessels, and the patient was treated with 2 units of packed red cells prior to surgery. Neither this patient nor any of the other patients in the present study experienced transient $(0 \%)$ or permanent $(0 \%)$ neurological deficits from preoperative embolization. As described in prior studies, spinal cord ischemia is rare, resulting in transient neurological deficits in 3\% of patients and permanent deficit in close to $0 \% .22$

\section{Limitations}

This work is limited by several factors. It is a retrospective study and thus may be subject to selection bias. It is also derived from the series of a single interventionalist at a single high-volume institution, which may affect the generalizability of the findings.

\section{Conclusions}

Surgical treatment of spine tumors can improve neurological function, deformity, instability, and pain. Hypervascular tumors pose a particular challenge, being associated with high intraoperative blood loss. Preoperative embolization can safely and effectively reduce blood loss at surgery. In this study, patients whose tumors were at least $90 \%$ embolized had significantly lower blood loss at surgery than those with only partial embolization. Importantly, there was no difference between complete and nearcomplete embolization, suggesting that there may be an effective minimum degree of embolization above which little additional benefit is gained.

\section{References}

1. Ahmed AK, Goodwin CR, Heravi A, et al. Predicting survival for metastatic spine disease: a comparison of nine scoring systems. Spine J. 2018;18(10):1804-1814.

2. Wright E, Ricciardi F, Arts M, et al. Metastatic spine tumor epidemiology: comparison of trends in surgery across two decades and three continents. World Neurosurg. 2018;114:e809-e817.

3. Pennington Z, Ahmed AK, Molina CA, et al. Minimally invasive versus conventional spine surgery for vertebral metastases: a systematic review of the evidence. Ann Transl Med. 2018;6(6):103.

4. Sundaresan N, Scher H, DiGiacinto GV, et al. Surgical treatment of spinal cord compression in kidney cancer. J Clin Oncol. 1986;4(12):1851-1856.

5. Grundy BL, Nash CL Jr, Brown RH. Deliberate hypotension for spinal fusion: prospective randomized study with evoked potential monitoring. Can Anaesth Soc J. 1982;29(5):452462.

6. Pull ter Gunne AF, Cohen DB. Incidence, prevalence, and analysis of risk factors for surgical site infection following adult spinal surgery. Spine (Phila Pa 1976). 2009;34(13):14221428.

7. Luksanapruksa P, Buchowski JMM, Tongsai S, et al. Systematic review and meta-analysis of effectiveness of preoperative embolization in surgery for metastatic spine disease. $J \mathrm{Neu}$ rointerv Surg. 2018;10(6):596-601.

8. Hong CGG, Cho JHH, Suh DCC, et al. Preoperative embolization in patients with metastatic spinal cord compression: mandatory or optional? World J Surg Oncol. 2017;15(1):45.

9. Kato S, Murakami H, Minami T, et al. Preoperative embolization significantly decreases intraoperative blood loss during palliative surgery for spinal metastasis. Orthopedics. 2012;35(9):e1389-e1395.

10. Zaborovskii N, Ptashnikov D, Mikaylov D, et al. Preoperative embolization and local hemostatic agents in palliative decompression surgery for spinal metastases of renal cell carcinoma. Eur J Orthop Surg Traumatol. 2018;28(6):1047-1052.

11. Sciubba DM, Petteys RJ, Dekutoski MB, et al. Diagnosis and management of metastatic spine disease. A review. J Neurosurg Spine. 2010;13(1):94-108.

12. Sundaresan N, Digiacinto GV, Hughes JEO, et al. Treatment of neoplastic spinal cord compression: results of a prospective study. Neurosurgery. 1991;29(5):645-650.

13. Bell GR. Surgical treatment of spinal tumors. Clin Orthop Relat Res. 1997;(335):54-63.

14. Bilsky MH, Lis E, Raizer J, et al. The diagnosis and treatment of metastatic spinal tumor. Oncologist. 1999;4(6):459469.

15. Gokaslan ZL, York JE, Walsh GL, et al. Transthoracic vertebrectomy for metastatic spinal tumors. J Neurosurg. 1998;89(4):599-609.

16. Walsh GL, Gokaslan ZL, McCutcheon IE, et al. Anterior approaches to the thoracic spine in patients with cancer: indications and results. Ann Thorac Surg. 1997;64(6):1611-1618.

17. Guzman R, Dubach-Schwizer S, Heini P, et al. Preoperative transarterial embolization of vertebral metastases. Eur Spine J. 2005;14(3):263-268.

18. Nair S, Gobin YP, Leng LZ, et al. Preoperative embolization of hypervascular thoracic, lumbar, and sacral spinal column 
tumors: technique and outcomes from a single center. Interv Neuroradiol. 2013;19(3):377-385.

19. Prabhu VC, Bilsky MH, Jambhekar K, et al. Results of preoperative embolization for metastatic spinal neoplasms. J Neurosurg. 2003;98(2)(suppl):156-164.

20. Kato S, Hozumi T, Takaki Y, et al. Optimal schedule of preoperative embolization for spinal metastasis surgery. Spine (Phila Pa 1976). 2013;38(22):1964-1969.

21. Kobayashi K, Ozkan E, Tam A, et al. Preoperative embolization of spinal tumors: variables affecting intraoperative blood loss after embolization. Acta Radiol. 2012;53(8):935-942.

22. Griessenauer CJJ, Salem M, Hendrix P, et al. Preoperative embolization of spinal tumors: a systematic review and metaanalysis. World Neurosurg. 2016;87:362-371.

23. Tan BWL, Zaw AS, Rajendran PC, et al. Preoperative embolization in spinal tumour surgery: enhancing its effectiveness. J Clin Neurosci. 2017;43:108-114.

24. Westbroek EM, Ahmed AK, Pennington Z, et al. Atypical vertebral hemangiomas are frequently associated with radiculomedullary arteries. World Neurosurg. 2019;127:e1215e1220.

25. Westbroek EM, Ahmed AK, Pennington Z, et al. Hypervascular metastatic spine tumor angiographic relationships with the artery of Adamkiewicz and other radiculomedullary arteries. World Neurosurg. 2019;126:e480-e485.

26. Kumar N, Tan B, Zaw AS, et al. The role of preoperative vascular embolization in surgery for metastatic spinal tumours. Eur Spine J. 2016;25(12):3962-3970.

27. Medsinge A, Zajko A, Orons P, et al. A case-based approach to common embolization agents used in vascular interventional radiology. AJR Am J Roentgenol. 2014;203(4):699-708.

28. Falanga A, Marchetti M, Vignoli A. Coagulation and cancer: biological and clinical aspects. J Thromb Haemost. 2013;11(2):223-233.
29. Takasawa C, Seiji K, Matsunaga K, et al. Properties of Nbutyl cyanoacrylate-iodized oil mixtures for arterial embolization: in vitro and in vivo experiments. J Vasc Interv Radiol. 2012;23(9):1215-1221.e1.

\section{Disclosures}

Dr. Gailloud: consultant for Longeviti Neuro Solutions and Cerovenus, support of non-study-related clinical or research effort from Siemens Medical, direct stock ownership in Artventi, and Grant funding from DePuy Synthes. Dr. Sciubba: consultant for Baxter, DePuy Synthes, Globus Medical, K2M, Medtronic, NuVasive, Stryker; and unrelated grant support from Baxter Medical, North American Spine Society, Stryker.

\section{Author Contributions}

Conception and design: Westbroek. Acquisition of data: Pennington, Ahmed, Xia, Boone. Analysis and interpretation of data: Westbroek, Gailloud. Drafting the article: Westbroek, Pennington. Critically revising the article: Sciubba, Westbroek, Pennington, Ahmed, Xia, Gailloud. Reviewed submitted version of manuscript: Sciubba, Westbroek, Pennington, Ahmed, Xia, Gailloud. Approved the final version of the manuscript on behalf of all authors: Sciubba. Statistical analysis: Westbroek. Study supervision: Sciubba.

\section{Correspondence}

Daniel M. Sciubba: Johns Hopkins University School of Medicine, Baltimore, MD.dsciubb1@jhmi.edu. 